Article

\title{
The Overview Effect and the Ultraview Effect: How Extreme Experiences in/of Outer Space Influence Religious Beliefs in Astronauts
}

\section{Deana L. Weibel}

Anthropology Department, Grand Valley State University, Allendale, MI 49401, USA; weibeld@gvsu.edu

Received: 30 June 2020; Accepted: 11 August 2020; Published: 13 August 2020

\begin{abstract}
This paper, based mainly on astronauts' first-person writings, historical documents, and my own ethnographic interviews with nine astronauts conducted between 2004 and 2020, explores how encountering the earth and other celestial objects in ways never before experienced by human beings has influenced some astronauts' cosmological understandings. Following the work of Timothy Morton, the earth and other heavenly bodies can be understood as "hyperobjects", entities that are distributed across time and space in ways that make them difficult for human beings to accurately understand, but whose existence is becoming increasingly detectable to us. Astronauts in outer space are able to perceive celestial objects from vantages literally unavailable on earth, which has often (but not always) had a profound influence on their understandings of humanity, life, and the universe itself. Frank Wright's term, the "overview effect", describes a cognitive shift resulting from seeing the Earth from space that increases some astronauts' sense of connection to humanity, God, or other powerful forces. Following NASA convention (NASA Style Guide, 2012), I will capitalize both Earth and Moon, but will leave all quotations in their original style. The "ultraview effect" is a term I introduce here to describe the parallel experience of viewing the Milky Way galaxy from the Moon's orbit (a view described reverently by one respondent as a "something I was not ready for") that can result in strong convictions about the prevalence of life in the universe or even unorthodox beliefs about the origins of humanity. I will compare Morton's ideas about humanity's increased awareness of hyperobjects with Joye and Verpooten's work on awe in response to "bigness", tying both to astronauts' lived experiences in order to demonstrate the usefulness of ethnographic data in this context, discuss how human experiences in outer space might influence religious practices and beliefs, and suggest that encounters with hyperobjects hold the potential to be socially beneficial.
\end{abstract}

Keywords: anthropology; religion; spaceflight; NASA; awe; astronauts; overview effect; ultraview effect

\section{Introduction}

Due to a longstanding association between celestial bodies and the supernatural, there are clear, cross-cultural connections between religious concepts (particularly of lofty places associated with helpful or threatening deities) and the sky (including cosmic objects like planets and stars that are visible within it). As George Lakoff and Mark Johnson (Lakoff and Johnson 1981) state in Metaphors We Live By, the sky "metonymically stands for heaven, the natural habitat of the Holy Spirit" (Lakoff and Johnson 1981, p. 40). The English language, for instance, includes a collection of words and phrases that can refer to both space and to supernatural ideas about the imagined abode of God, angels, and select human souls-heavenly, celestial, etheric, otherworldly, etc. Postulated supernatural places and outer space seem to occupy a similar metaphoric category in that they are not of the Earth, stretch beyond and above the world, and surpass the mundane. These metaphors seem to anticipate 
the strangeness humans actually feel in space, recognizing that as a species we evolved on, and within the specifications of, the particular planet we currently occupy.

In this paper, I examine a contemporary phenomenon that expands this apparent overlap between ideas of outer space and religious concepts, specifically experiences described by American astronauts during which their religious understandings were influenced or shaped by physically seeing sights (the Earth from space and vistas of stars from lunar orbit) that cannot be seen in the same way from Earth. In doing so, I demonstrate the utility of anthropological methods for learning what is really happening "on the ground" (so to speak) among astronauts and give examples of how religious practices might be influenced by the atypical sensations and visions available to astronauts. While Frank White's (White 2014) concept of the overview effect is important and has been an influence on many of the astronauts I cite, I argue that seeing the Earth from space is not the only potentially religiously transformative scene an astronaut can witness, introducing the concept of the "ultraview effect", a response to an unobscured view of stars that certain astronauts have described as life-changing. I analyze the way astronauts' viewings of the Earth and stars may contribute to religious feelings by evoking a sense of wonder, drawing on ideas of awe and human transformation from psychology and philosophy, and suggest such experiences could have a role to play in shaping the way human societies of the future react to overwhelming situations and phenomena.

\section{Background}

Valerie Olson, an environmental anthropologist, has done fascinating work on outer space as an "extreme environment" (Olson 2018). Noting the alien essence of outer space (in comparison to what we know on Earth), Olson explained that the term "nature" is not typically a term applied to the cosmos, and that this un-naturalness is plainly dangerous for humans who seek to venture into this extreme environment. She mentions, for instance, that "Without gravity's pull, blood and other fluids push upward and strain organ systems" (Olson 2018, Introduction, Location 96) and that radiation is a constant source of physical damage to humans in space. As an anthropologist of religion who sees human religious experience as fairly natural, adaptive, and typically falling within certain predictable constraints (see Boyer 2007), I'm interested in how and why individuals in space respond to their unearthly location. Anthropologists studying religion frequently borrow from other disciplines, with philosophy having a large theoretical influence in the anthropology of religion (see Bialecki 2016) and psychology (including evolutionary psychology) contributing much to religious understandings in cognitive anthropology (see, for example, d'Andrade 1995). Both disciplines, then, because of their focus on subjects' inner lives, are useful in exploring astronauts' religious experiences in outer space.

The strangeness humans tend to feel in space includes, from time to time, a sense of awe, particularly in situations where the enormity of the space around them (or of large bodies like the Earth or the Moon) becomes apparent. For the purposes of this paper I'm using the definition of awe provided by neuroscientist and science writer Summer Allen of the Greater Good Science Center at the University of California, Berkeley, in a white paper for the John Templeton Foundation (Allen 2018). Allen stated that awe is a "complex emotion that can be difficult to define. Feelings of awe can be positive or negative-Unlike most other emotions-And can arise from a wide range of stimuli" (Allen 2018, p. 2). She discussed theories that the feeling of awe evolved in humans because it may have "helped people identify safe places to seek shelter, such as environments with large vistas that would have allowed our hunter-gatherer relatives to see approaching predators or attackers" and suggested that it "may be adaptive because it encourages us to take in new information and adjust our mental structures around this information, helping us navigate our world and increasing our odds of survival" (Allen 2018, p. 2). Allen also argued that "awe's ability to make us feel more connected with others and to be more helpful and generous may have also helped ensure our ancestors' survival and reproductive success" (Allen 2018, p. 2). Allen cited Dacher Keltner and Jonathan Haidt's analysis (Keltner and Haidt 2003) of the origins of the word "awe" in English, where they tied it to Old English and Old Norse terms for "fear and dread, particularly toward a divine being" and defined the current word in English as 
"dread mingled with veneration, reverential or respectful fear; and the attitude of a mind subdued to profound reverence in the presence of supreme authority, moral greatness or sublimity ${ }^{1}$, or mysterious sacredness", although Allen noted that in contemporary English "awe" is often used to describe "a positive experience in nature" (Allen 2018, p. 7). When I refer to awe here (or use the similar term "wonder"), I mean the more complex sense of the term offered by Keltner and Haidt (2003).

Awe can be further explored through an analysis of the phenomena and situations that evoke the feeling. According to philosopher Timothy Morton, there exists a reality to certain huge objects or systems (he used the term "hyperobjects") that is separate from humanity's ability to perceive or judge them (Morton 2013). While human beings throughout the ages have had a slow but increasing awareness of large objects (like the globe or the ocean, for example), Morton specifically used hyperobject to refer to "massively distributed entities that can be thought or computered, but not directly touched or seen" (Morton 2013, p. 37), meaning our main awareness of them is achieved through the use of technology. These extreme phenomena (like "nuclear radiation" or "global warming") exist apart from the human ability to truly comprehend them. For Morton, human "contact" with these objects is transformative in a very disruptive way: " ... this is the moment at which massive nonhuman, nonsentient entities make decisive contact with humans, ending various human concepts such as 'world,' 'horizon,' 'nature,' and even 'environment.'” (Morton 2013, p. 39). Through this contact, our understanding is fundamentally altered.

Hyperobjects are normally phased, meaning we only see parts of them at any given time, so they seem to come and go. In this view, the reality of a thing exists apart from our piecemeal impressions of the reality of things, and at this point in time we are starting, slowly, to comprehend them in their entirety. Morton wrote, "This is the historical moment at which hyperobjects become visible by humans. This visibility changes everything. We humans enter a new age of sincerity, which contains an intrinsic irony that is beyond the aestheticized, slightly plastic irony of the postmodern age" (Morton 2013, p. 42). He explained that like hidden images in Magic Eye puzzles, hyperobjects have always been there, we just didn't know how to see them before due to their vastness, our incomplete understanding, and our previous lack of tools to help us perceive them (telescopes, Geiger countered, genetic analysis, etc.). Morton believes the human reaction to our newly sincere awareness of hyperobjects is "disgust" and "pain", as our familiar illusions are replaced with a frightening perception of something truly alien. Are disgust and pain the only possible responses? Morton sees humanity as a whole coming to grips with a huge, only partially perceivable reality. We are limited, most of the time, by our size and our incomplete vantage point. Astronauts in space, however, get to see a bit more of "real" reality than is typical, and their reactions seem to offer more optimism than suggested by Morton. ${ }^{2}$

Psychologists Yannick Joye and Jan Verpooten (Joye and Verpooten 2013) argued that monumental architecture, like the Egyptian pyramids and other large religious constructions, are effective in evoking religious thoughts and behavior because they trigger an evolved "sensitivity for bigness" (Joye and Verpooten 2013, p. 56) in the human mind. They contend that large, awe-inspiring structures create a specific "emotional charging" (Joye and Verpooten 2013, p. 64) that renders visitors more open to religious beliefs and supernatural explanations. For Joye and Verpooten, awe can trigger feelings of "admiration, beauty, delight, goose bumps, aesthetic chills, fear, dizziness, romance or hope", and that "exceptional vastness", in particular, makes those that experience it feel "physically insignificant" in a way that "challenges or 'shakes' an individual's cognitive conceptions, involving an inability to assimilate the awe-provoking experience into current mental structures" (Joye and Verpooten 2013, p. 57).

In a similar situation described by Piercarlo Valdesolo and Jesse Graham (Valdesolo and Graham 2013), psychological subjects made to experience awe responded first with uncertainty and then with an

1 See (Burke 1898) and (Kant 2003) for classic essays on the concept of the sublime, and specifically (in Kant) on the mathematical sublime, experienced when humans encounter something whose size is overwhelming.

2 For more on Timothy Morton's hyperobject concept and outer space, see (Oman-Reagan 2016). 
increased tendency to detect agency (where there was none) in an experiment. They explained, "(I)n the moment of awe, some of the fear and trembling can be mitigated by perceiving an author's hand in the experience" (Valdesolo and Graham 2013, p. 177), which made subjects more open to religious ideas and explanations. The aforementioned Keltner and Haidt (2003) broke down the experience of awe, describing it as a sense of vastness is followed by a resulting need for accommodation. They wrote, "awe can transform people and reorient their lives, goals, and values. Given the stability of personality and values... awe-inducing events may be one of the fastest and most powerful methods of personal change and growth" (Keltner and Haidt 2003, p. 312).

Awe is frequently present in religious contexts, and the creation of religious structures and situations that increase the likeliness that religious adherents will experience awe is quite common. These structures and situations are diverse, ranging from the large monuments discussed by Joye and Verpooten to the use of bullroarers to create a subsonic, unconscious sense of the numinous in the rituals of New Guinea's Ilahita Arapesh people, described by anthropologist Donald Tuzin (Tuzin 1984). In the West, as anthropologist Birgit Meyer wrote, " ... the craving for deep experiences that involve some kind of 'wow' ... has generated a veritable market for the production of wonder-working devices, body techniques and spectacular performances that are made to impress via strong sensations and feelings" (Meyer 2015, p. 22). All of the awe-inducing religions that have been studied by scholars (so far) have been constrained by their Earth-bound circumstances; indeed the human sense of the sacred and the numinous was formed on Earth. What happens to human religious understandings and expressions when they are removed from their "natural habitat" and relocated into what one of Olson's interlocutors called "the awfulness of real outer space" (Olson 2018, Conclusion, Location 3937)?

Although human presence in outer space has only been possible since the 1960s and our data about outer space-inspired awe and its impact on religion is quite limited, an analysis of what we do know may help us understand more about the relationship between awe and religious experience in general and the religious impact of the direct human experience of outer space more specifically. How does exposure to the enormous vistas of the Earth, Moon, and galaxy impact astronauts, and might there exist similar experiences for humans who never leave the planet?

In this paper I analyze two visual perspectives unavailable to earth-bound humans in terms of their subjective, sometimes religious, impact on astronauts and in terms of their potential cultural impact. While both have been reproduced in photographs, my respondents affirmed that photographs do not accurately convey the actual experience. The first is the view of Earth as seen from space, a vista that evokes the response journalist White (2014) has deemed the overview effect. White wrote that "The Overview Effect is a cognitive shift in awareness reported by some astronauts and cosmonauts during spaceflight, often while viewing the earth from orbit... It refers to the experience of seeing firsthand the reality that the Earth is in space, a tiny, fragile ball of life, 'hanging in the void,' shielded and nourished by a paper-thin atmosphere" (White 2014, p. 2). Human responses to the overview effect include a stronger sense of connection to life on the planet, a feeling of protectiveness, and a greater appreciation for the planet's beauty.

Yaden et al. (2016), in a psychological analysis of White's concept, wrote that "a distant view of Earth ... suggests totality ... The wholeness of the Earth makes it a symbol of almost all that is meaningful in human life; it has tremendous, perhaps absolute, conceptual vastness. Seeing it from a distance, when one is disconnected physically yet connected emotionally, conjures thoughts of home, of the entirety of one's world, and of mankind [sic] as a whole." They also noted the resulting awe experienced by many astronauts is a "broaden and build" type of emotion, not just pleasant to experience, but capable of increasing and improving the experiencer in terms of both psychological and social resources. "Positive emotions", they argued further, "have been suggested to improve cardiovascular health, facilitate better collaboration in groups and even enhance creativity" (Yaden et al. 2016, p. 4).

The second perspective is the view of space seen from outside the Earth's atmosphere, either from Earth orbit or lunar orbit, which I call the ultraview effect. Although it is similar to another term Frank 
White coined, the "universal insight," he sees the latter as "an intensification of the Overview Effect that brings a similar understanding of the nature of the universe and our place in it" (White 2018, Appendix B, Location 3014). My term, on the other hand, while borrowing its structure from White's original overview effect concept, is much less about an intensified feeling of connection to and protectiveness of our planet, and more about a very real sense of the limitations of what we know compared to the vastness of what we don't know. I chose the morpheme "ultra" in this context because it is the Latin term for "beyond" but is often used to mean the "extreme". If the overview effect is about an increased understanding and awareness of the earth after seeing it from the outside, and the universal insight is an increased understanding and awareness of "the universe and our place in it", the ultraview effect is a transformative sense of incomprehension and a feeling of shrinking or self-diminution ${ }^{3}$ that comes from seeing vistas that one is, to quote an astronaut I interviewed, "not ready for". While the overview effect has been studied a great deal and has become part of astronaut culture, the ultraview effect is all but unstudied, even though it seems to have had a tremendous impact on several astronauts who described it, and is a stronger example of a hyperobject, given the impossibility of seeing, experiencing, or understanding the totality of outer space.

Due to the fact that so many astronauts, both in publications and in interviews, have talked about changes to their religious beliefs or outlooks as a result of things they've experienced or seen in outer space, this paper will also consider the impact of the overview and ultraview effects on religious perspectives and understandings. According to anthropologist Clifford Geertz, religion is "a system of symbols which acts to establish powerful, pervasive, and long-lasting moods and motivations in men by formulating conceptions of a general order of existence and clothing those conceptions with such an aura of factuality that the moods and motivations seem uniquely realistic" (Geertz 1973, p. 90). I am using Geertz's definition in this paper, particularly its focus on how religion helps create a sense of a "general order of existence" with "an aura of factuality" that is "uniquely realistic". Geertz has argued that while humans share "a simple acceptance of the world, its objects, and its processes as being just what they seem to be" the "scientific perspective" encourages "Deliberate doubt and systematic inquiry" (Geertz 1973, p. 111). Similarly, religious texts, stories, etc. move "beyond the realities of everyday life to wider ones which correct and complete them" and it is "this sense of the 'really real' upon which the religious perspective rests" (Geertz 1973, p. 112). Briefly, both science and religion argue that there is far more to reality that meets the eye and experiences of awe, wonder, and contact with forces beyond the human capacity for understanding, such as those experienced by many astronauts, sometimes catalyze a change in what a person subjectively understands as "real", whether that change is to a more religious perception, a more scientific perception, or some novel fusion.

\section{Methodology}

I started my academic career as an anthropologist of pilgrimage and tourism, studying both the religious and secular uses of Catholic shrines. I have had a lifelong interest in space exploration and after marrying a former NASA employee, this interest, along with my knowledge of the subculture, grew. I conducted my first interview with an astronaut in 2004, but most of the scholarship undertaken for this article (following Research Ethics and Compliance training and approved by my university's

3 This sense of smallness was anticipated before any human actually went into space by many, and finds expression on a (Walter 1955) record album entitled Exploring the Unknown. The album depicts a fictional tour of the solar system and beyond, concluding with a song called "Look Up," with the lyrics:

Look up, look up, look up/Beyond the fading Sun./There's light enough that's bright enough/To keep the faith in everyone/Look up, look up, look up/And find a falling star/The hand divine that made it shine reminds us just how small we are/Orderly, they turn in space and someone was commanding all/Orderly, they burn in space and someone, somewhere planned it all/Look up, look up, look up/And watch the heavens glow/The more we see infinity/The more our faith will grow/Look up, look up, look up!!!!! 
Institutional Review Board) was carried out between 2017 and 2020. I have interviewed 37 "space workers" over the last three years, including physicists (several at the Vatican Observatory), engineers, test pilots, computer programmers, and physicians involved in space medicine. I have done fourteen interviews with nine astronauts so far.

Unsurprisingly given their renown, astronauts are typically the most difficult participants to make contact with, but using "snowball sampling", where one interviewee recommends another, I have been able to make several connections. Chaim Noy provided an excellent analysis of snowball sampling, a research "tactic" used in ethnographic work where "the researcher accesses informants through contact information that is provided by other informants. This process is, by necessity, repetitive: informants refer the researcher to other informants who are contacted by the researcher and then refer her or him to yet other informants, and so on" (Noy 2008, p. 330). In my case, since I've interviewed multiple types of space workers, I have made contacts with astronauts through a space historian, an astronomer, and, of course, through other astronauts. Noy pointed out that snowball sampling, "arguably the most widely employed method of sampling in qualitative research" (Noy 2008, p. 330), is particularly useful when trying to interview groups that are somewhat protective of their identities. He explained that while it is often used to initiate research with members of marginalized groups, it can also be helpful to access people who "enjoy the status of social elites" (Noy 2008, p. 331), see also (Moyser and Wagstaffe 1987). Astronauts and others whose work in or about space puts them in the public eye are often justifiably wary when approached, so being connected through a mutual acquaintance helps establish the trust and rapport that ethnographic research requires.

This research also falls under what George Marcus has called multisited ethnography (Marcus 1995). Astronauts and other space workers don't live in a single community, but are spread wide and far among different communities. Therefore, as an anthropologist I have immersed myself in "space culture", not in a single "village", but by entering the workspaces of many of my interlocutors, attending (and presenting at) engineering and space medicine conferences, visiting NASA flight centers, and even going to space-focused conventions. I have conducted interviews in hotel lobbies, academic offices, restaurants, a pilot's lounge, and a convention center meeting room, among other places, as well as via telephone calls and video chat programs like Zoom. While some astronauts were eager to talk about their religious beliefs, others only spoke to me after I explained the conventional use of pseudonyms in most ethnographic work, wanting to keep their religious ideas (or lack of them) private. In general, retired astronauts are far more likely to consent to an interview than active astronauts, probably because opening up about a controversial topic like religion, even when one's identity is hidden, seems at least potentially risky. I have also relied on the public talks and published memoirs of astronauts, following the precedent of space ethnographers like Debbora Battaglia (Battaglia 2012).

Data collection from just my own primary sources resulted in hundreds of pages of interview transcripts and field notes. I took these, along with my notes from secondary sources, and undertook a process of careful coding and content analysis, during which I identified units of meaning, determined code terms, categorized information, and distinguished and connected different themes. My principal interest in this part of my research was the subjective experiences of astronauts in space, looking for both common patterns and for singular perceptions based on unique circumstances, which I was then able to compare with existing reports from anthropology, psychology, and other disciplines.

\section{Ethnographic Data}

As mentioned above, following anthropological convention, I used pseudonyms for my participants and also may have occasionally changed small identifying details to help preserve the anonymity of my interlocutors. I started with astronauts for whom the overview effect, if it existed at all, was mild, then moved through others whose experiences were more dramatic, and sometimes even interpreted religiously. I then turned to reports that support the idea of an ultraview effect, discussing how and why it appears distinct from the overview effect. 
Paul, in his 70s at the time of our interview, made multiple space shuttle flights and was one of the lucky few who never experienced motion sickness in space and deeply enjoyed the opportunity to walk across ceilings, sit on walls and do other perception-altering things afforded by microgravity. He told me:

Everybody who flies in space comes back a little different ... [but] I didn't develop any sort of spiritual awakening or that kind of thing by being in space. When you look out the window, you look at the Earth, and you recognize that we are seven and a half billion people who all share this one planet together, and the question that always crossed my mind was why can't we get along? So, I think that occurred to me. And then I developed more of an ecological bent more than anything else... And you recognize how fragile this planet is and how important it is for us to take care of it.

Alan, a retired astronaut in his early 50s who flew more recently than Paul, made a few trips to the International Space Station. His first time there he was excited about the possibility of experiencing the overview effect, having been told about it by other astronauts. Alan said:

I remember before I flew in space, [two colleagues] spoke very eloquently about it in some of their transmissions from [their shuttle] and so I was aware of it and I was prepared to have a very transformative moment. The first time I looked out at the Earth from space ... I even intentionally paused and kind of collected myself and meditated a little bit to kind of clear my head before I opened my eyes and looked out the window for the first time. And I didn't really feel anything. It's kind of a letdown. There was nothing. And maybe it's because I'm not a spiritual person, that's quite possible ... It was a beautiful sight and a unique vantage point, but there was nothing about it that I felt in any way unlocked any kind of philosophical mysteries or spiritual mysteries.

Like Paul, seeing the Earth from space, particularly the thin blue line of the atmosphere (which he described as a "very vivid, graphical depiction of the fragility of our planet" that "just gave me a better appreciation"), made Alan more sensitive to issues like climate change, but he felt little in terms of awe and no great revelations about humanity. He explained, somewhat flippantly:

As far as the Overview Effect and getting a sense that we are a common humanity, and we all share a common home, and at the end of the day that the things that unite human beings are commonalities between human beings that are greater than the things that divide us ... You know, I think the reason that I didn't come away with some kind of sudden, strong compelling feeling in that regard is that I think I knew that before I left.

Beverly, who became an astronaut after working for NASA in other capacities, was quite religious in her personal life but didn't find the view of the Earth from the shuttle particularly perspective changing. She attributed this, as Alan did, to having learned the lessons the overview effect was meant to teach before ever going into space. Beverly said:

On a personal level ... and this is, I think wrapped into the whole idea of the overview effect, when I came back, the things that really resonated with me [were] at the simple base level of it. We live on a planet, we're all earthlings, the only border that matters is this line of atmosphere that blankets us all. And I knew those things before I flew to space. I didn't think of them very much.

Still, knowing those things and seeing them firsthand were different. She continued:

It's this experience that puts that reality in your face in a way that you can't deny. You're like, "Oh my gosh, that is a planet. Look at that, everybody I know is down there, it's really beautiful." All those things. "Look at that little super thin, wafer thin line that's all around it. Wow, it's holding all the good stuff in." That kind of thing. You don't have to go to space for 
this ... I want my children to understand that. They might not ever get to go to space, but I don't want them to have to think, "Oh I have to go to space to be able to appreciate that."

Alan and Beverly were both in their fifties at the time of their interviews and grew up in a time when images of the Earth taken from space, like the famous "Earthrise" photograph taken by Apollo 8 Lunar Module Pilot William A. Anders (who himself reported becoming less religious in response to seeing the Earth from space ${ }^{4}$ ), were commonplace. As Frank White suggests, even a photograph of the entire Earth may be enough to change people's perceptions of the planet by showing the entirety of the planet as a bounded, singular object, whether or not they traveled in space ${ }^{5}$.

On the other hand, the overview effect for Tom, a veteran in his 80 s who began working for NASA during the Apollo era, did seem to change his sense of the world. In his public talks he has frequently mentioned realizing that national borders were artificial or seeing that we were just one planet. In our interview, however, he focused on the religious insight he gained from going into space and how it reinforced his existing spiritual understandings. He explained:

The space experience in my view, if one doesn't believe in God, I don't see how they can't be drawn just a little closer to having had it ... When you're up there, I never felt an ethereal experience ... but the experience is something that you can't really prepare for in terms of how it's going to affect your life later. And I think it has. It didn't do so immediately ... You don't realize how much it affects your life until later on, but everything you do after that has something of that perspective in it. Even subconsciously. And to me, I notice that I'm not patient at all with trivia... Because I've seen the bigger picture.

Paul, Alan, Beverly, and Tom, though their experiences were quite different, felt they understood more about earth, humanity, and the "bigger picture" after seeing earth from space.

Don, another Apollo-era octogenarian, described seeing the Earth from space somewhat differently. When he discussed being an astronaut, he typically compared it unfavorably to the satisfaction and fulfilment of being a Christian, an approach that was carried over in the way he talked about seeing the Earth from space. For example, Don characterized the experience as a way to verify the veracity of the Bible. He explained to me:

I believe God has given us the signs in the heaven that most people don't recognize ... There are scriptures like 'God sits enthroned above the circle of the earth'. Well, with my eyes, I've seen the circle of the earth ... and when that was written way, way, 800 years before Jesus, nobody had seen the circle of the earth, but God had .... And in the book of Job, there's a verse that says, when God made the earth, he suspended it upon nothing. And that's exactly what it looks like ... the Bible is not a textbook or science book, but when it touches on science, it's accurate I've seen.

Looking at the Earth from space was worthwhile for Don, though, even beyond giving him a chance to witness biblical descriptions first-hand. When I mentioned a paper by Damjanov and Crouch (Damjanov and Crouch 2019) that suggested that the view during suborbital tourism might be less than optimal and that virtual reality could "extend or complete the experience" (Damjanov and Crouch 2019, p. 134), he disagreed, responding:

4 Bill Anders has discussed his own reaction to seeing the Earth from space in interviews, and the experience apparently jolted him into a very different religious mindset, one more closely associated with atheism. Perhaps the sense of the "really real" he had learned in church was contradicted by what he saw. In an interview with The Guardian, he explained, "It really undercut my religious beliefs. The idea that things rotate around the pope and up there is a big supercomputer wondering whether Billy was a good boy yesterday? It doesn't make any sense. I became a big buddy of [the scientist] Richard Dawkins" (Sample 2018).

5 The negative outcomes of "whole Earth" photographs were explored in a fascinating essay by (Garb 1985). Garb argued that the "icon" of the Earth from space may make humans disassociate themselves from the planet and feel unrealistically independent from it, homogenize the Earth's distinct cultures and climates, and unconsciously reduce the Earth from a living thing to a mechanical machine. White, of course, sees the image in a much more positive, less critical light. 
I told my friend on his [planned] Virgin Galactic flight, don't unstrap, just look out the window ... You can do zero gravity on an airplane-five thousand bucks and you can do zero gravity. But you'll never have a view like you're going to have by looking out the window to see the curvature of the Earth and the beauty of the Earth from 400,000 feet, it's five minutes. It will change your life. Look out the window.

The idea of the overview effect appears to have penetrated the culture of astronauts, and those new to space travel, like Alan, have learned to expect a dramatic subjective response of some kind. Reactions, though, seem to be as variable as the people who experience them. Theo, a veteran of many missions, entertained himself by watching first-time astronauts respond to the view of the Earth from orbit, but, as a very spiritual person himself, knew internal experiences were not always readable by observers. He told me:

I've flown with [many] rookies and I've seen them, bang! First time that it hit them. And I'm a people watcher. So my general conclusion is I have a hard time seeing any changes in them. But If you look at [me] you probably don't see the changes either ... it doesn't mean they did not have a spiritual experience.

Theo liked to include distant pictures of Earth taken from robotic probes in his public presentations, hoping these views could enact some kind of change in those who saw them. These distant views of the Earth, he explained, provide:

... a perspective that if it were to guide human beings, we would be different.... (T)hose views can guide us as human beings. If you look upon it [as though] we all are sharing this little spaceship, it would guide our behavior differently. We wouldn't be at war all the time. We would have respect for other humans on that journey together.

My unavoidably small sample size of astronauts, as limited as it was, included both people for whom looking at the Earth from space inspired them spiritually and those for whom it did not. Firm conclusions cannot be reached from this ethnographic data, but the first-hand experiences of these astronauts suggest that human response to seeing the Earth from space is variable, that astronauts are socialized through interactions with more experienced colleagues to expect some sort of response, and that the experience of seeing our planet as an external, separate "thing" can shift the way people understand the reality of being a human on Earth, particularly if the view they see of a borderless, fragile orb is at odds with what they have previously understood. A heightened understanding of the hyperobject that is our planet, from a heretofore unseen perspective, clearly has the potential, at least, to enact interior change.

Every astronaut I've interviewed has had an opinion of and some kind of experience of the overview effect. The second visual experience I want to examine, what I call the ultraview effect, is comparatively rare and hard to come by. From what those who have experienced it report, it seems to require two things: first, circumstances where the viewer is primed to experience awe, and second, the ability to see the space around oneself under very specific, hard-to-arrange conditions. As we turn to the ultraview effect, I want to focus on the experiences of an eighth astronaut, seventy-something Charles, a fundamentalist-turned-Lutheran shuttle veteran with a profound interest in theology and an agnostic commitment to honestly representing what he does not know. Charles' experience of the overview effect was relatively modest, although enjoyable. He told me about one memorable incident:

Part of the earth had turned away from the sun (which is where the auroras are) and the Aurora Australis was active and, oh yeah, you can see waves in it. And also, this was the period of the Perseids shower. So, while I'm watching this, I'm seeing shooting stars below me in the atmosphere. And it was pretty awesome. And ... there was a sense, I was just surprisingly comfortable there. And so, as I thought back over it that's when I started thinking that, really, that humans might have a future in space. 
Charles' God's-eye view of the Earth's atmospheric phenomena didn't overturn or intensify his religious beliefs, but the ease with which he experienced it did make him more certain that the human exploration of space was worthwhile.

Though Charles was one of hundreds of humans to see the planet from orbit, he was only one of a far smaller group to see stars as they do not, and cannot, look from the Earth. Due to the special circumstances of his mission, Charles was able to look out into space and really see it in an unusual way. He climbed into a camera bay, shut the Velcro curtains around his waist and let himself become dark-adapted. Although the experience was striking, it didn't create the same sense of wonder he experienced looking at Earth. He explained, "You are very aware of the sky being full of stars and you're also very aware of the colors of them ... I was much more aware of the color and much more aware of the numbers and the patterns. It was just beautiful." Charles' description of his view of the Earth, however, was more vivid and he was clearly more emotionally engaged while looking down at the planet than when looking at the stars, however beautiful they were.

Charles had a rare situation where he was able to get fully dark-adapted before seeing the stars, but the typical workload on, and view from, an orbiting shuttle or from the International Space Station does not generally permit this, making it even less likely that an astronaut will see an incredible stellar view. As Alan (who never got dark-adapted, to his regret) explained, looking at the stars from orbit:

... is hard, you have to work at it to look the other way, at least from the Space Station, because almost all the windows pointed at the Earth ... it doesn't look that much better than it does from down here. There's no atmospheric distortion, so the stars are a little bit brighter and ... they don't flicker-the twinkling of course, you don't get that. But otherwise, if you'd go out to Joshua Tree ${ }^{6}$ on a really good clear night it kind of looks like that.

Getting further away from the Earth seems to help with the conditions, although even then the direction of sunlight and the absence or presence of shadows makes a difference. Some of the Apollo astronauts wrote about what they could or could not see of the stars in the open spaces around them. John Young (Young and Hansen 2012), Command Module Pilot of Apollo 10 (which orbited the Moon and practiced maneuvers ahead of Apollo 11's first lunar landing), wrote in his memoir, "Because of the light reflected back off Earth into my telescope optics—and it didn't take much—seeing any stars while you were still flying in the vicinity of Earth was very difficult" (Young and Hansen 2012, p. 128). James Irwin and William A. Emerson (Irwin and Emerson 1982), Lunar Module Pilot for Apollo 15, who frequently credited his experience on the Moon with reinstating his Christian beliefs, did not see much of a stellar view. He explained that during a spacewalk with Command Module Pilot Alfred Worden, " . . there was so much of the sun's reflected light on the vehicle that I couldn't see the stars" (Irwin and Emerson 1982, p. 100). As for the view of stars from the Moon itself, Charles Duke, Lunar Module Commander for Apollo 16, said, "Stars don't look any different from the moon than they do from earth" (Duke and Duke 2011, Sweet Sixteen Has Arrived!, Location 2517).

While it is very common to have unimpressive views of stars while journeying in space, several astronauts who were able to get away from nearly all earthly or artificial sources of light have written about seeing views of the cosmos around them that were overwhelming. While in orbit around the Earth, Michael Collins (Collins 1974) left his Gemini 10 craft to do an extra-vehicular activity in near-total darkness ("the moon is not up and the only identifiable light comes from an occasional lightning flash") and described his experience as deeply overwhelming, writing:

My first impression is a feeling of awe at the wide visual field, a sense of release after the narrow restrictions of the tiny Gemini window. My God, the stars are everywhere: above me on all sides, even below me somewhat, down there next to that obscure horizon. The stars are bright and they are steady. Of course, I know that a star's twinkle is created

6 Joshua Tree is a national park in the California desert designated as a "Dark Sky Park". 
by the atmosphere, and I have seen twinkle-less stars before in a planetarium, but this is different; this is no simulation, this is the best view of the universe that a human has ever had. (Collins 1974, pp. 220-21)

Edgar Mitchell, Lunar Module Pilot for Apollo 14, was known for his exploration of the limits of human consciousness, conducting experiments in extrasensory perception during his Apollo mission and later founding the Institute of Noetic Sciences to help study the type of instantaneous knowledge he claimed to have received about the unity of the universe and humankind while in space. Perhaps unsurprisingly, then, he described experiences viewing outer space that brought about awe and a subjective shift in perception. His full experience is often conflated with the overview effect, which was certainly an element of what he described, but parts of it seem much closer to the ultraview effect. Mitchell said about space, "There is a sense of unreality here, with the absence of gravity and the tapestry of blackness broken only by an overwhelming glitter of stars that surrounded our craft", (Mitchell and Williams 2008, p. 61) and explained further:

In space there are nearly 10 times more stars visible to the naked eye than on earth because there is no atmosphere. Likewise, familiar objects are approximately 10 times brighter. Stars and planets seem to burn against the cool blackness. There is the sense of being swaddled in the cosmos, surrounded by the beautiful silent glitter of the Milky Way and all the galaxies beyond". (Mitchell and Williams 2008, p. 73)

Tied to this sensation was a strange awareness: "Somehow I felt tuned into something much larger than myself, something much larger than the planet in the window. Something incomprehensibly big. Even today the perceptions still baffle me" (Mitchell and Williams 2008, p. 74). Like the overview effect, the ultraview effect has the potential to evoke formidable, overpowering emotions and alter human perception, although it may be more likely than the overview effect to do so. Collins appears to have experienced a taste of it (although he did not describe a transformative effect), while Mitchell described his consciousness of himself and reality as having been truly changed. Mitchell's description also recalls Morton's "massively distributed entities" that can be sensed but not truly understood (Mitchell and Williams 2008, p. 37).

The only astronaut I have interviewed so far who had a deep emotional reaction to and internal transformation from the view of stars he had from the deep darkness of space was an Apollo crewmember in his 80s, whom I call Zack, who spent several days in orbit around the Moon while the rest of his crew explored the lunar surface below. Although he was busy with NASA assignments, he did take time to take in the view outside his window. He stated in one of our interviews:

Looking at the universe out there from my vantage point, I began to realize that we don't know crap about anything, we really don't ... (A)t some points in my orbit around the moon, I was sheltered from both the earth and the sun, so I was in complete darkness. And all of a sudden, the star patterns out there became something that I was not ready for ... So many stars I couldn't see one. Just a sheet of light. I don't know whether you'd call it spiritual or not, but when I saw the starfield out there in a way that nobody else has ever seen ... I had some pretty profound thoughts... We are not unique in the universe. When I came back from my flight, we were all totally exhausted ... I'd sit in my living room and all these thoughts would come flowing through, so I began writing them down ... They flowed from my mind through a pen onto a piece of paper. It was like I was being guided by something ...

Zack wrote poetry as a way of processing his time in space. One of his poems describes seeing light from various perspectives, including the "starfield" he mentioned to me, and how he was blinded and left unable to think because of the enormity of its light. For Zack, the experiences of total solitude in orbit, an incomprehensible sheet of light, microgravity, and exhaustion all combined to influence his reckoning with something he didn't understand. The sheer number of stars he saw convinced him that other intelligent beings must exist throughout the universe. He gradually began to modify 
certain beliefs from his conventional mid-line Protestant upbringing, reading theories about life being brought to Earth by alien races and became convinced, for instance, that the long lives of biblical figures like Noah proved they were descended from extraterrestrials who created humanity and that the "wheel" mentioned in the Book of Ezekiel was a description of an alien spaceship. Zack was a rational person, a successful author and businessman, but his unconventional religious beliefs were absolutely influenced by his time in space, which he said changed his idea of infinity and his whole outlook. He concluded, "We are not unique in the universe. I happen to believe we came from somewhere else."

\section{Analysis and Conclusions}

Published accounts by other astronauts frequently include descriptions of strong responses to being in space, whether the renewed Christianity of the aforementioned James Irwin (Irwin and Emerson 1982) of Apollo 15, who went on to search for Noah's ark on Mt. Ararat, or the metamorphosis experienced by Apollo 14's Mitchell and Williams (Mitchell and Williams 2008), whose "palpable" experience of divinity and connection in space, described above, led to a life-long exploration of the noetic transmission of knowledge. Why do some of these experiences, particularly those of the Apollo astronauts who journeyed much farther into space than those who have followed them, seem to work as catalysts to change astronauts' religious or spiritual perspectives?

It is certainly possible that participating in unusual, historic occurrences, whether journeying to the Moon in the 1960s, winning the lottery, or surviving a terrible disaster, can make an individual question why an event happened and wonder whether a supernatural being or power is somehow involved. The astronaut I call Tom, for instance, thought his whole life was guided by divine forces. He said, "I believe God can direct a person's life; I think God has a plan for every person's life. And if there's a relationship with him where there's a two-way conversation and there's a real attempt to have a personal God that he can direct a person's life." Tom's life was unusual in that he had a large share of adventure, success, and fame, and he was able to explain this through religious means. He frequently explained that God gave him the experience of being an astronaut, in part, to make him a more effective evangelist. Fame provides an audience. At the same time, however, when he was orbiting the Earth and seeing the planet as the creation of a "master engineer", something else was going on.

Many people live and die on Earth without ever having conscious awareness that we are on a literal sphere that rotates in space, orbiting a star. The sun, for them, is a brightly glowing light in the sky during the day and the Moon is a softly glowing light at night, with the reality of the solar system, galaxy, and universe something beyond real comprehension or interest. For some others there is an awareness of and curiosity about the bodies that can be viewed through telescopes and via images returned by probes or described in great detail by scientists, with real knowledge largely supplemented by imagination. Actually going into space, though, leaving the protective atmosphere of the planet and looking back at this round rock we all inhabit is very uncommon and deeply strange. The reality of the experience cannot be ignored or denied by those undertaking it. Astronauts may grow used to the sight of the terrain below them, but there is a shared cultural understanding in their ranks that seeing the roundness of the planet, the thin blue atmosphere, and the colors and weather patterns that shift with time is a rare gift. When the Apollo astronauts saw the Moon close up and even walked on it, they experienced an interaction with the real face of a largely imagined object that no one else had ever had before or has had since. Astronauts are often treated as super-human (see Weibel 2019), and while part of that is likely due to how competitive the astronaut selection process is, some of what impresses the general public is that astronauts have seen a level of reality, of truth, beyond what the vast majority of us will ever experience.

Astronauts have first-hand encounters with the Earth, the Moon, and, to some extent, the stars, which increase and improve our species' understandings of these objects, adding field data to what we can glean from telescopes, probes, and mathematics. The Apollo missions meant that the Moon was transformed from a mysterious cratered hyperobject to an actual "place" where people walked, golfed, and drove (see Messeri 2016). Our technology has allowed a massive increase in our knowledge, 
both mediated via robotic probes and first-hand, of massive celestial bodies. Humanity's awareness of hyperobjects, true confrontations with the extreme, is increasing daily, and examples from astronaut experiences suggest these confrontations can be qualitatively improved, made more pleasant and more conducive to astronauts' psychological wellbeing, through some kind of cultural mediation. Astronauts learn from other astronauts that they may see something special "up there" and, at least some of the time, respond in ways that make them humbler, more thoughtful, and, occasionally, more open to religious and spiritual beliefs ${ }^{7}$. The awesome sights astronauts can view from space might easily have inspired fear or disgust. For instance, Zack described the "hostility" of the "very unfriendly ... very unforgiving" Moon and how from even inside a spacecraft where he knew he was safe, he could sense the danger of the place: "You are so cut off from everything you know and here all of a sudden you're looking at the Moon that you probably looked at thousands of times growing up, and here you are anywhere from 60 to 10 miles away from it, and it's ... different." If more experienced astronauts continually described the Moon as "hostile" and "unfriendly" to less experienced astronauts, this would likely condition the new astronauts to interpret the Moon in a negative way, much as stories passed astronaut-to-astronaut about seeing the Earth from space seem to have conditioned astronauts to expect the overview effect. They anticipate awe, some, but not all, experience it, and among those who do are those who respond to the "cognitive shaking" that results by discarding long-held beliefs (religious or otherwise) and embracing a (literal) new worldview.

Experiencing the true nature of huge, seemingly incomprehensible objects creates awe, fear, and wonder, which can be stressful. The work (discussed earlier) by psychologists Joye and Verpooten (2013), Valdesolo and Graham (2013), and Keltner and Haidt (2003) suggests that situations that cause awe are fundamentally disturbing, but that responses that detect superhuman agency or result in personal transformation often provide relief. Tom's interpretation of the Earth as a product of God's engineering, Zack's conviction that there was intelligent life on other planets that led to life on Earth, and even milder reactions, like the increased ecological concerns of Alan, Paul, and Beverly are all examples. As we become increasingly cognizant of more of the hyperobjects Morton describes (including, at the time of this writing, COVID-19 spreading across the world in a pandemic), there is an opportunity to shape our need for accommodation in socially constructive ways. An experience of awe or of being overpowered can be channeled into positive outcomes, even social transformation, and humanity may benefit, rather than suffer, from being made to confront the extreme in outer space and elsewhere. For instance, Yaden et al. associated feelings of awe with increased creativity and ability to collaborate (Yaden et al. 2016, p. 4). When a person or community's sense of what is "really real" is transformed, particularly if this new "reality" is seen in a welcome light, there may be additional benefits, including increased morale and motivation (Yaden et al. 2016, p. 8). Studying the subjective responses of those who confront hyperobjects, particularly using ethnographic techniques that highlight the cultural context and shared, mediated experience of these reactions, can shed light on what may improve the experience of these unsettling encounters.

Frank White argued that the shared context of astronauts is what enables them to expect and easily process the overview effect. Astronaut Ed Gibson reinforced this with his comment, "The more who go, the more difference it will make" (White 2014, p. 7). Zack's sense of the "hostility" of the Moon was likely conditioned, to some degree, from reports from earlier Apollo astronauts like Edwin "Buzz" Aldrin, who famously characterized the satellite as a place of "magnificent desolation." A lack

7 While the ultraview effect is based on what an astronaut sees, not all transformative experiences in space are visual. The aforementioned Theo, who liked to watch other astronauts see the Earth from space for the first time, conducted a sort of sensory deprivation-style meditation in space on multiple occasions. He would put himself into a what he called a "perfect drop," a recreation of the womb experience of the human embryo, where he would float in the spacecraft in the dark, touching nothing, hitting no walls, and losing all sense of having a body. He said, "... it's totally being lost. It's totally Buddhist. And then you lose track of your limbs because... you have flexors and extensors [telling you] ... gravity's pulling my arm down here and it's stretching one or the other, but here in the embryonic, every single joint is in a neutral state ... Nothing pushing 'em ... So you lose track of your limbs. There's nothing to tell you you have limbs." 
of shared experience with other astronauts, however, likely made Zack's ultraview encounter with the "starfield" more dramatic, and even traumatic, than it would have been otherwise. He didn't interpret it in terms of Mitchell's "noetic" experience and largely processed it on his own. In contrast, the experience of the overview effect, which, when carefully anticipated and normalized in astronaut culture, typically provides astronauts with reassuring context. If humans can learn to culturally prepare for hyperobjects like those encountered in space, including planning for the "fear and trembling" that follows, there may be benefits. Jackie, an active NASA astronaut I interviewed before she was assigned to her first mission, told me:

Obviously, I haven't been to space so I haven't seen it, but a lot of times people mention the most amazing kind of emotion that they have when they launch into space as the first time they get to turn and look back at our planet and to see, you know, this beautiful blue marble and complete black blackness that people say you can't even describe until you see it.

NASA astronauts are clearly preparing each other to experience awe, which might mitigate any shock by defining the experience of seeing the Earth from space as a good one, but also may act, in some cases, as a self-fulfilling prophecy. Despite the somewhat disappointing experiences of Alan and Paul (and probably a few others) if an astronaut expects that seeing the Earth from space will be a positive, moving experience, the expectation makes the positive response more likely.

Morton argued that the human response to most hyperobjects is fear, disgust, and pain - the shock-filled emotions experienced by those realizing their limited capacity to respond to or control something literally incomprehensible. We seem to be better prepared for the unfathomability of outer space than we are for global warming, nuclear radiation, and pandemic illness. While some of our dismay with certain hyperobjects may come from the sense that we are somehow responsible for creating them but at a loss to how to manage them (climate change, mass extinctions, and the hole in the ozone layer come to mind), those that may not be directly influenced by human actions may be easier to see as having a divine origin or as being under divine control-religions around the world have tied their ideas about the sky to notions of gods, goddesses, ancestors, and the supernatural. Danger may come from the sky in the form of meteors, solar flares, etc., but we also look to the sky for help. If Valdesolo and Graham are correct, and the "fear and trembling" can subside and be replaced with what Yaden et al. describe as the psychologically beneficial experience of awe, inspiring determination and optimism if we somehow can imagine a greater plan at work (as did both Ed Mitchell and "Zack", whose perceived "greater plans" countered mainstream religion) this might prepare us to face other largely incomprehensible phenomena head-on. More scholarship needs to be done on this, particularly ethnographic work, which can help us understand these processes not just among astronauts (and cosmonauts, and other publicly and privately funded spacefarers in multiple societies), but also among scientists, physicians, and others who study the edges of hyperobjects, trying to bring human understandings in line with realities that seem, at least at first, to be unknowable.

The number of astronauts I have interviewed is small, and while ethnographic interviews provide rich data, they do not establish larger trends. I would encourage additional research in this area, both large-scale quantitative work like surveys to get a sense of the scale and scope of astronaut experiences (as well as similar experiences among cosmonauts and other spacefarers working with other national and private organizations), and ethnographic work, which has been extremely limited in this population, but has the potential to reveal individual thoughts and experiences that would otherwise be left undiscovered. These two approaches should guide each other, with phenomena brought to light by one method further analyzed by the other. Personal experience is irreplaceable, as suggested by a well-known characterization of the overview effect made by aforementioned astronaut Ed Mitchell "You develop an instant global consciousness, a people orientation, an intense dissatisfaction with the state of the world, and a compulsion to do something about it. From out there on the moon, international politics look so petty. You want to grab a politician by the scruff of the neck and drag him a quarter of a million miles out and say, 'Look at that, you son of a bitch'” (People Weekly 1974, p. 23). If Mitchell was right, our willingness to confront hyperobjects and to recognize what little we know 
and how much we still have left to learn may encourage better collaboration, heightened creativity, and set us upon a more hopeful path.

Funding: This research was funded by the Center for Scholarly and Creative Excellence and by the Department of Anthropology at Grand Valley State University, Allendale, Michigan, USA.

Conflicts of Interest: The author declares no conflict of interest.

\section{References}

Allen, Summer. 2018. The Science of Awe. West Conshohocken: John Templeton Foundation.

Battaglia, Debbora. 2012. Coming in at an Unusual Angle: Exo-Surprise and the Fieldworking Cosmonaut. Anthropological Quarterly 85: 1089-106. [CrossRef]

Bialecki, Jon. 2016. "Religion" after Religion, "Ritual" after Ritual. In The Routledge Companion to Contemporary Anthropology. Edited by Simon Coleman, Susan B. Hyatt and Ann Kingsolver. London: Routledge, pp. 199-216.

Boyer, Pascal. 2007. Religion Explained: The Evolutionary Origins of Religious Thought. New York: Basic Books.

Burke, Edmund. 1898. An Essay on the Sublime and Beautiful. London: Cassell, vol. 88.

Collins, Michael. 1974. Carrying the Fire; The Fire Carrier Tells It like It Was (Apollo 11). New York: Farrar, Straus and Giroux.

d'Andrade, Roy G. 1995. The Development of Cognitive Anthropology. Cambridge: Cambridge University Press.

Damjanov, Katarina, and David Crouch. 2019. Virtual Reality and Space Tourism. In Space Tourism: The Elusive Dream. Edited by Erik Cohen and Sam Spector. Bingley: Emerald Publishing Limited, pp. 117-38.

Duke, Charlie, and Dotty Duke. 2011. Moonwalker. Murfreesboro: Rose Petal Press.

Garb, Yaakov J. 1985. The use and misuse of the whole earth image. Whole Earth Review 45: 18-25.

Geertz, Clifford. 1973. The Interpretation of Cultures. New York: Basic Books, vol. 5019.

Irwin, James B., and William A. Emerson. 1982. To Rule the Night: The Discovery Voyage of Astronaut Jim Irwin. Nashville: Holman Bible Publishers.

Joye, Yannick, and Jan Verpooten. 2013. An Exploration of the Functions of Religious Monumental Architecture from a Darwinian Perspective. Review of General Psychology 17: 53-68. [CrossRef]

Kant, Immanuel. 2003. Observations on the Feeling of the Beautiful and Sublime. Berkeley: University of California Press.

Keltner, Dacher, and Jonathan Haidt. 2003. Approaching Awe, a Moral, Spiritual, and Aesthetic Emotion. Cognition and Emotion 17: 297-314. [CrossRef] [PubMed]

Lakoff, George, and Mark Johnson. 1981. Metaphors We Live By. Chicago: University of Chicago Press.

Marcus, George E. 1995. Ethnography in/of the World System: The Emergence of Multi-Sited Ethnography. Annual Review of Anthropology 24: 95-117. [CrossRef]

Messeri, Lisa. 2016. Placing Outer Space: An Earthly Ethnography of Other Worlds. Durham: Duke University Press.

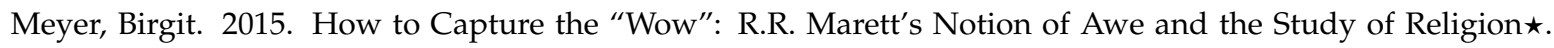
Journal of the Royal Anthropological Institute 22: 7-26. [CrossRef]

Mitchell, Edgar D., and Dwight Arnan Williams. 2008. The Way of the Explorer: An Apollo Astronauts Journey through the Material and Mystical Worlds. Franklin Lakes: New Page Books.

Morton, Timothy. 2013. Poisoned Ground: Art and Philosophy in the Time of Hyperobjects. Symplokē 21: 37-50. [CrossRef]

Moyser, George, and Margaret Wagstaffe, eds. 1987. Research Methods for Elite Studies. London: Allen and Unwin.

Noy, Chaim. 2008. Sampling Knowledge: The Hermeneutics of Snowball Sampling in Qualitative Research. International Journal of Social Research Methodology 11: 327-44. [CrossRef]

Olson, Valerie. 2018. Into the Extreme U.S. Environmental Systems and Politics beyond Earth. Minneapolis: University of Minnesota Press.

Oman-Reagan, Michael P. 2016. Unfolding the Space Between Stars: Anthropology of the Interstellar. OSF, July 20. Available online: https://osf.io/uaqmw/ (accessed on 30 June 2020).

People Weekly. 1974. Bio: Edgar Mitchell'S Strange Voyage. April 8, pp. $20-23$. 
Sample, Ian. 2018. Earthrise: How the Iconic Image Changed the World. The Guardian, December 24. Available online: https://www.theguardian.com/science/2018/dec/24/earthrise-how-the-iconic-image-changed-theworld (accessed on 23 July 2020).

Tuzin, Donald. 1984. Miraculous Voices: The Auditory Experience of Numinous Objects [and Comments and Replies]. Current Anthropology 25: 579-96. [CrossRef]

Valdesolo, Piercarlo, and Jesse Graham. 2013. Awe, Uncertainty, and Agency Detection. Psychological Science 25: 170-78. [CrossRef] [PubMed]

Walter, Schumann. 1955. "Look Up." Exploring the Unknown. New York: RCA Victor.

Weibel, Deana L. 2019. Astronauts vs. Mortals: Space Workers, Jain Ascetics, and NASA's Transcendent Few. The Space Review. Available online: http://www.thespacereview.com/article/3690/1 (accessed on 23 July 2020).

White, Frank. 2014. The Overview Effect: Space Exploration and Human Evolution. Reston: American Institute of Aeronautics and Astronautics.

White, Frank. 2018. The Cosma Hypothesis: Implications of the Overview Effect. New York: Morgan Brook Media.

Yaden, David B., Jonathan Iwry, Kelley J. Slack, Johannes C. Eichstaedt, Yukun Zhao, George E. Vaillant, and Andrew B. Newberg. 2016. The Overview Effect: Awe and Self-Transcendent Experience in Space Flight. Psychology of Consciousness: Theory, Research, and Practice 3: 1-11. [CrossRef]

Young, John, and James R. Hansen. 2012. Forever Young: A Life of Adventure in Air and Space. Gainesville: University Press of Florida.

(C) 2020 by the author. Licensee MDPI, Basel, Switzerland. This article is an open access article distributed under the terms and conditions of the Creative Commons Attribution (CC BY) license (http://creativecommons.org/licenses/by/4.0/). 